\title{
SPATIALISATION OF RICE GROWTH AND YIELD MODEL USING OPTICAL AND SAR DERIVED BIOPHYSICAL PARAMETERS
}

\author{
Anima Biswal ${ }^{* 1}$, S Srikanth $^{1}$, CS Murthy ${ }^{1}$ and PVN Rao ${ }^{2}$ \\ ${ }^{1}$ Agricultural Sciences \& Applications- anima.biswal@gmail.com, srikanth_p@nrsc.gov.in, murthy_cs@nrsc.gov.in \\ ${ }^{2}$ Remote Sensing Applications Area- rao_pvn@ @nrsc.gov.in \\ National Remote Sensing Centre, Balanagar, Hyderabad-500037
}

Commission III, WG III/10

KEY WORDS: Sentinel 1A, SAR, DSSAT, CERES, Phenology, Spatialisation

\begin{abstract}
:
Integration of remote sensing derived biophysical parameters with process based crop growth simulation model is an emerging technology with diversified application for crop insurance as well as precision farming. Basically the crop growth simulation models are point based which simulate crop growth and yield as a function of soil, weather and crop management factors at a daily time scale. The temporal dimension of the crop growth model is supplemented by the spatial information on crop coverage and condition generated from remote sensing satellite derived biophysical parameters. In the present study an attempt is made to simulate pixel wise rice crop growth, condition and yield using Sentinel1 SAR, AWiFS/Landsat8 OLI and MODIS data with CERES rice growth simulation model on DSSAT platform. Temporal SAR data provides pixel wise start of season for rice crop at a spatial resolution of $10 \mathrm{~m}$. Spectral indices derived from Landsat8/AWiFS and MODIS optical images are used for characterisation of rice growth environment and at the same time these indices are used to generate crop management information like irrigation and sowing dates. Bhadrak district of Odisha in the eastern coast of India is selected as the study area based on the prevalence of diversified rice growing environments. Sufficient in season field data are collected for checking the accuracy of rice map as well as for calibration and validation of the crop growth model. In season rice growth is initialised using SAR derived staggered sowing dates along with daily weather data and soil inputs. As CERES crop growth models are running well on DSSAT environment, rice crop growth simulation is carried out using multi date SAR images on DSSAT platform. The output of this study is maps depicting the spatial variability in rice area, staggered sowing dates and irrigation in the study region. These in season information are crucial for decision making particularly for crop insurance related activities.
\end{abstract}

\section{INTRODUCTION}

The use of crop growth models on large areas for monitoring crop growing conditions or predicting crop production is limited by the lack of sufficient spatial information about model inputs. Therefore, many different studies have attempted to estimate crop yield in combination of process based crop growth simulation model and satellite data. Remote sensing and crop growth modelling are two distinct technologies that have been developed to address diverse agronomic issues at fieldlevel and regional scales (Moran et al., 1997; Batchelor et al.,2002; Xie et al., 2008). Although these technologies have often been developed independently, there is growing interest in utilizing information derived from remote sensing to update or drive cropping systems model simulations because the two technologies are naturally complementary (Maas, 1988a; Moulin et al., 1998; Inoue, 2003; Dorigo et al., 2007). For example, the daily time-step simulation capabilities of crop simulation models are excellent for crop growth analyses in the temporal domain, where as temporal satellite images and derived indices offer great opportunity to understand spatial crop growth patterns. Conversely, detailed model input requirements have limited the use of crop growth simulation models for spatial crop growth analyses. With the integration of these technologies, the problems associated with one can be compensated by the benefits of the other. Spatialisation of crop models needs to link different scales. For example, the scale on which the processes are described by the model, (Moulin et al.,1998) and the scale on which input data or information (model parameters and input variables) are available, or the scale on which output results are expected or sought. Thus, spatialisation often requires some kind of change of scale, and in this aspect remote sensing plays a vital role in providing spatialised inputs for crop simulation on regional scale. The Decision Support System for Agro Technology Transfer (DSSAT) is a comprehensive decision support system that includes the Cropping System Models CERES/ORYZA for simulating rice crop growth and yield. It has been successfully employed over the last 30 years worldwide in many range of applications, including climate change, precision agriculture and crop. management such as nitrogen fertilization, irrigation and sowing date (Arora et al., 2007; Biswal et al., 2014;Cabrera et al., 2007; Rinaldi et al., 2007; Rinaldi and Ubaldo, 2007; Brassard and Singh, 2008; Thorp etal., 2008; Timsina et al., 2008; Luo et al., 2009; Ventrella et al., 2009; Ventrella et al., 2012; Iqbal et al., 2011).

In Odisha, rice is grown under diverse ecosystems and a wide range of climatic conditions. The immense diversity in growth conditions makes classification and characterization of the rice environments a challenging task. Rice is cultivated on an area of 4.45 million hectares, which can be classified into six different ecosystems: irrigated kharif $(27.4 \%)$, rainfed upland $(19.1 \%)$, medium land $(12.4 \%)$, shallow lowland $(22.5 \%)$, semi deep $(7.9 \%)$, deep $(3.4 \%)$, and irrigated rabi $(7.4 \%)$. Accurate and timely assessment of the spatial distribution of the rice cropped

\footnotetext{
* Corresponding author
} 
area is a key information for the stakeholders including policy makers. Mapping of the rice cropped area using the optical data during the kharif season is difficult due to persistent clouds during this season. In this context SAR data provides the solution as the microwave wavelengths can penetrate through cloud making the SAR sensors all weather capable. Not only the rice cropped area but also the date of transplantation of the rice crop is also one of the key inputs for the crop simulation models. With the launch of Sentine-1, SAR data is available at every 12 days interval from the last few years and has been widely used by the many researchers for the rice crop mapping and monitoring (Nguyen et al., 2016; Nguyen and Wagner, 2017; Xin Zhang et al., 2018). In this study, rice cropped area is mapped from temporal backscattering coefficient and also the information on the date of transplantation of the rice crop has been generated using multi date SAR images. This date of transplantation information has been used as the start of season information to initialise the crop growth model. The broad objective of this study is to develop a methodology for integrating SAR derived biophysical parameters of rice crop with a process based crop growth model.

\section{MATERIALS AND METHODS}

\subsection{Study Area}

Due to prevalence of diverse rice ecology in Bhadrak district of Odisha,it is selected as the study area .The district is situated in the north-eastern part of Odisha and lies between north latitudes $20045^{\prime} \& 2101^{\prime}$ ' and east longitudes 860 17' \& 860 59' (Plate - I). It is bounded in the north by Balasore, in the south by Kendrapara and Jajpur, in the west by Keonjhar districts and in the east by Bay of Bengal. The total mean annual rainfall is $1427.6 \mathrm{~mm}$ of which around $1020 \mathrm{~mm}$ is received from SW monsoon during June-September. The average lowest and the highest temperatures for the district are $13.80 \mathrm{C}$ and $38.70 \mathrm{C}$ respectively. In general, three groups of soils are found in the district of bhadrak. These soil groups are classified in to Matured, red \& lateritic soil (alfisols), mixed grey soil (inceptisols), unaltered soils with coarse parent materials (entisols) and Unclassified soil (with mud flats). The net sown area in the district is $173 \mathrm{Ha}$. and the cropping intensity is $138 \%$.Rice is the major crop in Kharif followed by pulses like green gram and black gram. The present irrigated area of Bhadrak district of the state of Odisha is $64.4 \%$ in kharif season ( $1,08,268$ ha) while only $20.1 \%$ in rabi season ( $33,897 \mathrm{ha})$. The rain fed areas are subjected to high risk of crop production. The erratic behavior of monsoon significantly affects the production of the district as the cultivation in un-irrigated areas is subjected to high risk and is a less productive farming profession.

\subsection{Meteorological data}

The maximum and minimum temperatures from Automatic Weather Station of IMD (Indian Meterological Department) were used in the study. The data has been downloaded from the IMD website and the weekly averages were generated for the test sites. Since the historical data from AWS is not available, the nearby meteorological observatory data is being used. Daily average maximum, minimum temperature $\left(0^{\circ} \mathrm{C}\right)$, rainfall $(\mathrm{mm} /$ day) and solar radiation $(\mathrm{MJ} / \mathrm{m} 2)$ are the prerequisites for running DSSAT CERES model. For model calibration and validation, historical weather data (IMD) from 1998 to 2013 were used.

\subsection{Soil input}

Layer-wise soil attributes like texture, sand (\%), silt (\%), clay $(\%)$, bulk density $(\mathrm{g} / \mathrm{cm} 3)$, field capacity $(\mathrm{cm} 3 / \mathrm{cm} 3)$, permanent wilting point $(\mathrm{cm} 3 / \mathrm{cm} 3)$, saturated soil water content $(\mathrm{cm} 3 / \mathrm{cm} 3)$, saturated hydraulic conductivity $(\mathrm{cm} / \mathrm{h})$, organic carbon $(\%), \mathrm{pH}$ and electrical conductivity $(\mathrm{dS} / \mathrm{m})$ are required to run the model. The NBSSLUP soil map and secondary information from district database maintained by CRIDA (Central Research Institute for Dry Land Agriculture) have been used for preparing the soil input files.

\subsection{Calibration and validation of CERES-DSSAT}

The CERES rice model version 4.6 of the DSSAT modeling system which is an advanced physiologically based rice crop growth simulation model was used to predict rice (Swarna) growth, development, and response to various climatic conditions. This was through determination of duration of growth stages, dry matter production and partitioning, root system dynamics, effect of soil water and soil nitrogen contents on photosynthesis, carbon balance, and water balance, followed by sensitivity analysis to assess the effects of change in weather conditions on Swarna grain yield. The cultivar coefficient was determined with thermal time from emergence to the end of juvenile stage $(\mathrm{P} 1)$, rate of photo induction $(\mathrm{P} 2 \mathrm{R})$, optimum photoperiod (P2), thermal time for grain filling (P5), conversion efficiency from sunlight to assimilates (G1), tillering rate (TR), and grain size $(\mathrm{G} 2)$.

Required weather and soil files were prepared according to DSSAT format and crop simulation was carried out for Swarna rice variety as this variety is commonly grown in Bhadrak. The crop management data (i.e., agronomic data) required by the model include planting date, planting density, row spacing, planting depth, fertilizer application dates, and amounts was collected from field experiments. Soil data involved collection of set of input data on soil characteristics at $5 \mathrm{~cm}$ and $25 \mathrm{~cm}$ depths before and during the cropping season on soil classes, bulk density, organic carbon (\%), sand silt clay (\%). The data includes soil texture, $\mathrm{pH}$ of soil in water, organic carbon, cation exchange capacity, total nitrogen, potassium, and phosphorus. The growth and development modules of the CERES model use different sets of species, ecotype and cultivar coefficients. For calibration, the cultivar coefficients were obtained sequentially, starting with the phenological development parameters related to flowering and maturity dates followed by the crop growth parameters related with kernel filling rate and kernel numbers per plant. These parameters were adjusted to minimize root mean square error (RMSE) between simulated and measured data. . A good match was obtained between observed and simulated grain yield with a RMSE of 0.817 t/ha and a normalized RMSE (RMSEn) of $14.943 \%$. An index of agreement for grain yield closer to $1(0.869)$ also revealed that the model performed well in predicting the yield. The regression analysis gave a coefficient of determination $\left(R^{2}\right)$ value of 0.778 . In general, the results from the model validation indicate that CERES rice version 4.6 was able to predict growth and development for Swarna variety in a good manner and therefore can be applied as a study tool.

\subsection{Methodology}

The broad methodology of the study is presented in Fig1.After successful calibration and validation, the model is run in spatial 
domain for the rice pixels of $10 \mathrm{~m} * 10 \mathrm{~m}$ using Sentinel $2 \mathrm{~A}$ optical and sentinel 1A SAR data.

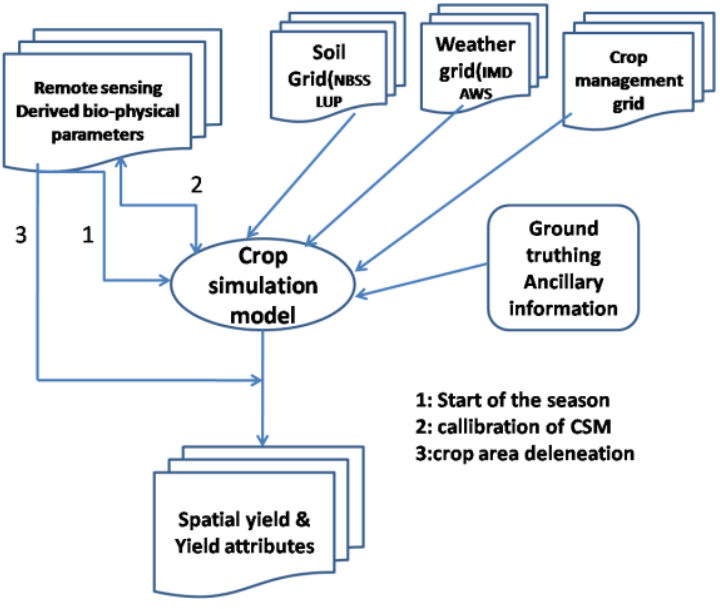

Figure 1. Flowchart of methodology

Temporal Sentinel-1A Synthetic Aperture Radar (SAR) operating at C-band and acquired in interferometric Wide Swath (IW) mode at $5 \mathrm{~m} \times 20 \mathrm{~m}$ (azimuth $\mathrm{x}$ range) spatial resolution with a swath width of $250 \mathrm{~km}$ have been used in this study. The Ground Range Detected (GRD) products resampled to $10 \mathrm{~m}$ pixel spacing have been used.

The data was processed for radiometric calibration, speckle suppression and terrain correction using ESA's SNAP Tool Box. Refined Lee speckle filter has been used for the speckle suppression while the SRTM 30m Digital Elevation Model (DEM) was used during the Range Doppler Terrain Correction. Further all the data were converted to Sigma naught (Backscattering coefficient). The backscatter statistics of selected training sites for rice crop were generated and the temporal backscatter profiles were plotted. The decision rules for rice crop classification were formulated based on the temporal backscatter response and a rule based classification approach was used to delineate the rice cropped pixels. Land Surface Wetness index derived from sentinel $2 \mathrm{~A}$ is used as a proxy for irrigation input to the model.

\section{RESULTS \& DISCUSSION}

\subsection{Result}

From the temporal backscatter profiles (Fig-2), it can be seen that there is a sudden decrease in the backscatter of rice crop due to specular reflection from the standing water in the fields during puddling/transplantation phase of the rice crop and the value of which was ranged from around $-21.6 \mathrm{~dB}$ to $-15.8 \mathrm{~dB}$ (VV-polarization) and gradually the backscatter increased with the crop growth and remained plateau during the month of October.
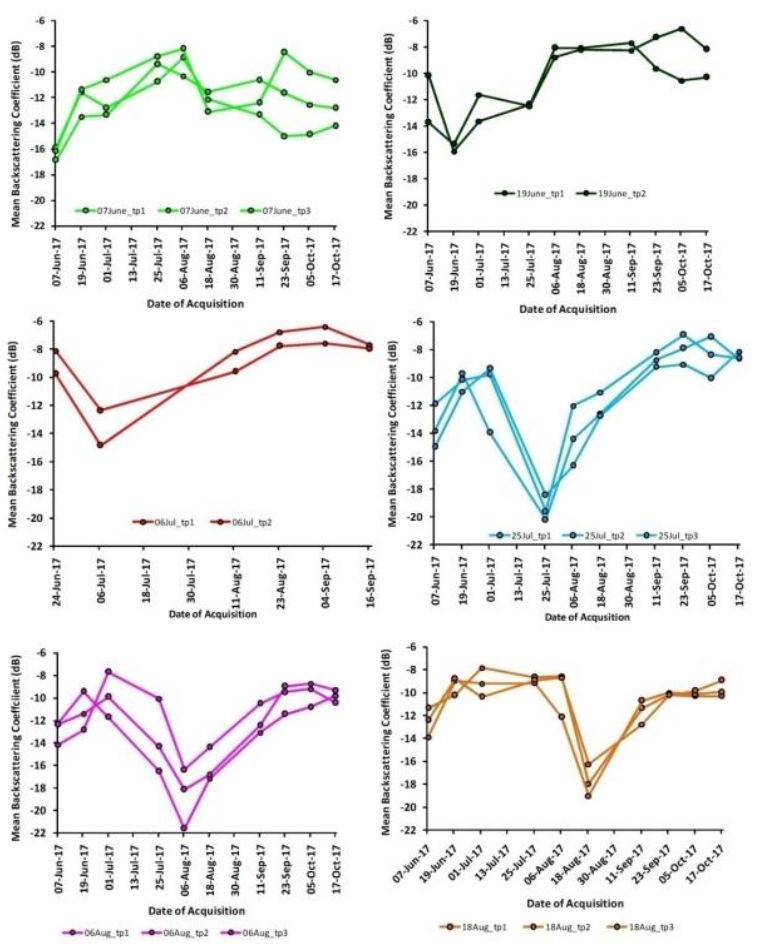

Figure 2. Temporal Backscatter profiles of rice crop in Bhadrak district, Odisha.

This forms the basis for the identification of the rice crop from temporal SAR data. The rice cropped area derived from the decision rule based classification of temporal backscatter was found to be 1,24,997 hectares in Bhadrak district for the kharif2017 season. The RGB of the temporal SAR and the classified rice map are shown in Fig-3 and Fig-4 respectively.

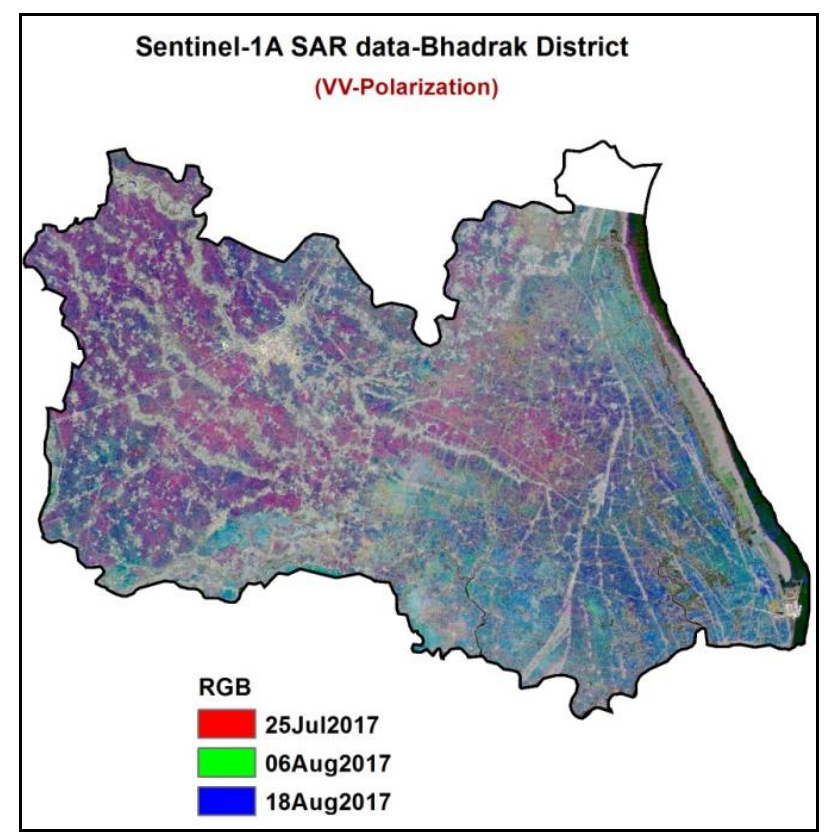

Figure.3. RGB of Sentinel-1A SAR data. 


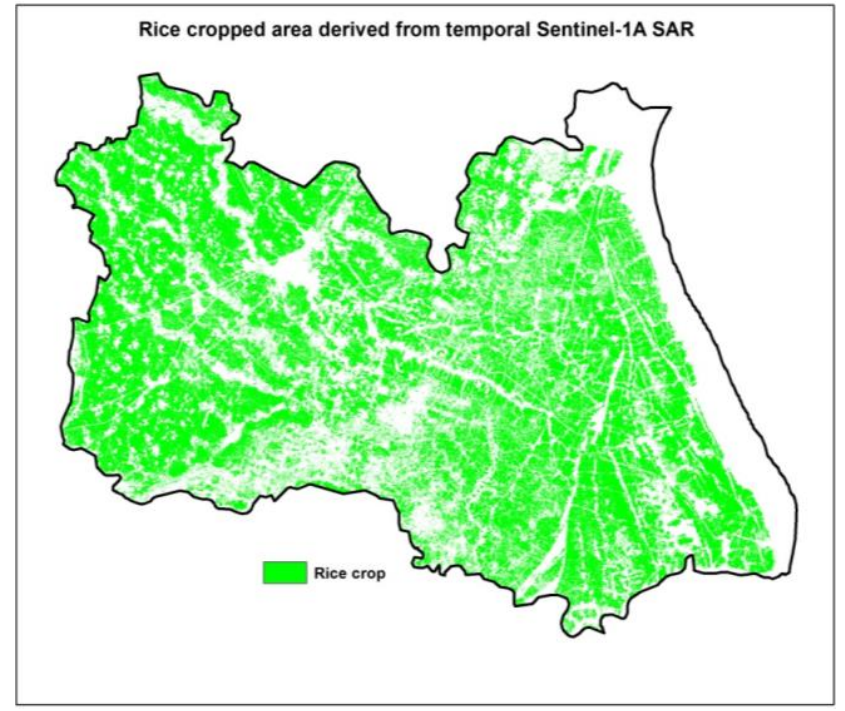

Figure.4. Classified map of rice cropped from Sentinel-1A SAR data

It is also observed that the dip is not uniformly over the same date but seen over June, July and August dates which indicates the staggering of the transplantation of the rice crop in this district from June-September. The staggering in the sowing/transplantation of the rice crop is mapped and is spatially depicted in Fig-5.

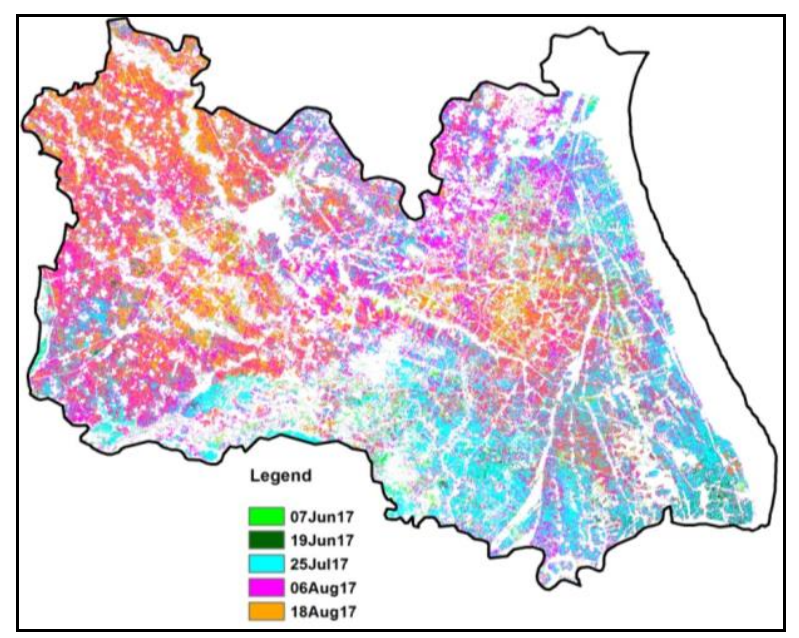

Figure.5. Staggering of the rice crop transplantation mapped from Senrinel-1A SAR

All the inputs like weather, soil and crop management information are fed to the spatialised CERES crop growth model in a semi automated mode. The rice area and start of the season information along with the irrigation proxy derived from LSWI are the major remote sensing derived spatialised inputs. Three irrigation proxies were generated based on LSWI representing rainfed, limited irrigation and optimum irrigation condition for kharif rice in Bhadrak district during 2017.Staggered sowing date/start of the season information derived from multi-temporal SAR images are fed into the model. The result shows that the yield varies from 950-4500 $\mathrm{Kg} / \mathrm{ha}$ which is comparable with the in-season field level CCE.
It is also observed that in more than $60 \%$ of the rice area the simulated yield is higher than $3000 \mathrm{Kg} / \mathrm{ha}$. Pixel wise $\left(10 \mathrm{~m}^{*} 10 \mathrm{~m}\right)$ simulated rice yield for the kharif rice area in Bhadrak is represented in Fig.6. Other biophysical parameters like LAI, total dry matter etc., are also simulated with reasonable accuracy. The simulated phenology information like days to anthesis, days to physiological maturity etc., are in good agreement with the field observations.

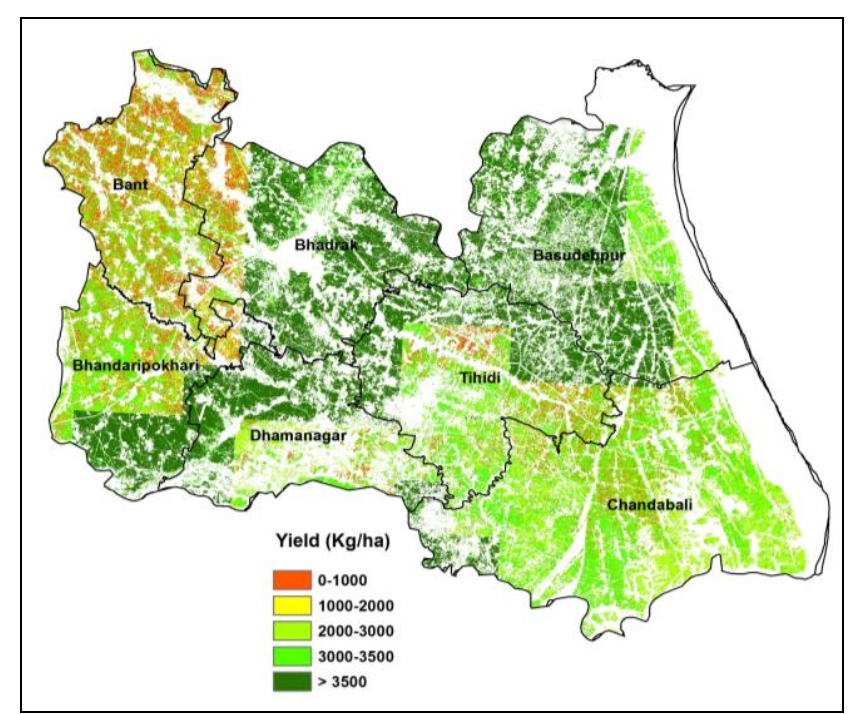

Figure.6. Simulated Yield map for Kharif rice in Bhadrak during 2017

\subsection{Conclusion}

This study is a methodology demonstration for integrating microwave derived biophysical parameters with crop growth model particularly for rice crop. As start of the season is a very sensitive parameter for the crop model, this methodology can be adopted for initialising the model using temporal SAR data. Irrigation treatment is another sensitive and important parameters for crop growth simulation, LSWI is a potential tool for generating irrigation proxies. The result of the this study will be further evaluated with the results obtained from assimilation of remote sensing parameters in to the model and run time calibration

\section{REFERENCES}

Arora VK, Singh H, Singh B. 2007. Analyzing wheat productivity responses to climatic, irrigation and fertilizernitrogen regimes in a semi-arid sub-tropical environment using the CERES-Wheat model. Agriculturall Water Management, 94: pp. 22-30

Batchelor, W. D., B. Basso, and J. O. Paz. 2002. Examples of strategies to analyze spatial and temporal yield variability using crop models. European J. Agron. 18(2): pp. 141-158.

Biswal A, Sahay B, Ramana KV, Rao SVC, Sesha Sai MVR. 2014. Relationship between AWiFS derived Spectral Vegetation Indices with Simulated Wheat Yield Attributes in Sirsa district of Haryana. The International Archives of the Photogrammetry, Remote Sensing, pp. 689-694 
Brassard JP, Singh B. 2008. Impacts of climate change and $\mathrm{CO} 2$ increase on agriculture production and adaptation options for southern Québec, Canada. Mitigation and Adaptation Strategies for Global Change,13: pp. 241-265

Cabrera VE, Jagtap SS, Hildebrand PE 2007. Strategies to limit (minimize) nitrogen leaching on dairy farms driven by seasonal climate forecasts. Agriculture, Ecosystems \& Environment, 122:pp. 479-489

Dorigo, W. A., R. Zurita-Milla, A. J. W. de Wit, J. Brazile, R.Singh, and M. E. Schaepman. 2007. A review on reflective remote sensing and data assimilation techniques for enhanced agroecosystem modeling. Intl. J. Applied Earth Observation and Geoinformation 9(2): pp. 165-193.

Duy Ba Nguyen and Wolfgang Wagner, 2017. " European Rice Cropland Mapping with Sentinel-1 Data: The Mediterranean Region Case Stusdy". Water, 9, pp. 392; doi:10.339/w9060392.

Duy Ba Nguyen, Alexander Gruber and Wolfgang Wagner, 2016. "Mapping rice extent and cropping scheme in the Mekong Delta using Sentinel-1A data". Remote Sensing Letters, Vol.7, No.12, pp.1209-1218.

Inoue, Y. 2003. Synergy of remote sensing and modeling for estimating ecophysiological processes in plant production.Plant Production Sci. 6(1): pp. 3-16.

Iqbal MA, Eitzinger J, Formayer H, Hassan A, Heng LK 2011. A simulation study for assessing yield optimization and potential for water reduction for summer-sown maize under different climate change scenarios. Journal of Agricultural Sciences, 149: pp. 129-143

Luo Q, Bellotti W, Williams M, Wang E. 2009. Adaptation to climate change of wheat growing in South Australia: Analysis of management and breeding strategies. Agriculture, Ecosystems \& Environment, 129:pp 261-267

Maas, S. J. 1988a. Use of remotely-sensed information inag ricultural crop growth models. Ecological Modelling 41(3-4): pp. 247-268.

Moran, M. S., Y. Inoue, and E. M. Barnes. 1997. Opportunities and limitations for image-based remote sensing in precision crop management. Remote Sensing of Environ. 61(3): pp 319346.
Moulin, S., A. Bondeau, and R. Delecolle. 1998. Combining agricultural crop models and satellite observations: From field to regional scales. Intl. J. Remote Sensing 19(6): pp. 10211036.

Rinaldi M, Ubaldo R, 2007. Simulation at regional level of irrigated wheat and tomato in a Mediterranean environment. Water Resources Management, 4: pp. 569-581

Rinaldi M, Ventrella D, Gagliano C. 2007. Comparison of nitrose and irrigation strategies in tomato using CROPGRO model. A case study from Southern Italy. Agricultural Water Management, 87: pp. 91-105

Thorp KR, DeJonge KC, Kaleita KL, Batchelor KD, Paz JO. 2008. Methodology for the use of DSSAT models for precision agriculture decision support. Computers and Electronics in Agriculture, 64: pp. 276-285

Timsina J,Godwin D, Humphreys E, Singh Y, et al. 2008. Evaluation of options for increasing yield and water productivity of wheat in Punjab, India using the DSSAT-CSMCERESWheat model. Agricultural Water Management, 95: pp. 1099-1110

Ventrella D, Charfeddine M, Moriondo M, Rinaldi M, Bindi M. 2012. Agronomic adaptation strategies under climate change for winter durum wheat and tomato in southern Italy: irrigation and nitrogen fertilization.Regional Environmental Change, 12(3): pp. $407-419$

Ventrella D, Rinaldi M, Charfeddine M, Ruggieri S, et al. 2009. Adattamento ai cambiamenti climatici per frumento duro e pomodoro in ambiente Mediterraneo: irrigazione $\mathrm{e}$ concimazione azotata. Atti XXXVIII Conv. Naz. Società Italiana di Agronomia, pp. 67-68, Firenze, Italy

Xie, Y., Z. Sha, and M. Yu. 2008. Remote sensing imagery in vegetation mapping: A review. J. Plant Ecology 1(1): pp. 9-23.

Xin Zhang, Bngfang Wu, Guillermo E.Ponce-Campos, Miao Zhang, Sheng Chang and Fuyou Tian, 2018. " Mapping up-toDate Paddy Rice Extent at 10M Resolution in China through the Integration of Optical and Synthetic Radar Images". Remote Sens.2018, 10, pp. 1200; doi: 10.3390/rs10081200. 